\title{
FARKLI IŞIK KAYNAKLARININ RENKLİ KOMPOMERLERİN MİKROSERTLİĞİ ÜZERİNE ETKİSİ
}

\section{THE EFFECT OF DIFFERENT LIGHT-CURING UNITS ON THE MICROHARDNESS OF COLORED COMPOMERS}

\author{
Dr. Öğr. Üyesi Münevver KILIÇ*
}

Arş. Gör. Dt. Gönül YETER*

Makale Kodu/Article code: 4476

Makale Gönderilme tarihi: 26.06 .2020

Kabul Tarihi: 06.10.2020

DOI: $10.17567 /$ ataunidfd. 806638
Münevver Kılıç: ORCID ID: 0000-0002-3470-0430

Gönül Yeter: ORCID ID: 0000-0003-1959-5879

\section{öz}

Amaç: Bu çalışmanın amacı üç farklı ışık cihazı ile polimerize edilen renkli kompomerlerin yüzey sertlik değerini karşılaştırmaktır. Gereç ve yöntem: A2 glasiosite (Voco, Almanya), pembe Twinky Star (Voco, Almanya), mavi Twinky star (Voco Almanya) kullanılarak, 5mm-2mm kalınığında 72 örnek hazırlanmıştır. Örnekler Valo Cordless (Ultradent - ABD), D-Light Pro (GC Almanya) ve Woodpecker (Çin) ışık cihazları ile polimerize edilmiştir. Örneklerin yüzey sertlik değer ölçümleri Vickers mikrosertlik cihazı ile yapılmıştır.

Bulgular: Yüzey sertliği değerlendirildiğinde kompomer rengi ve ışık cihazı arasında etkileşim bulunmamaktadır $(p=0,104)$ (Univariate analysis, Two way anova). Kompomerlerin yüzey sertlik değerleri karşılaştırıldığında GC ışık cihazı Valo'dan istatistiksel olarak anlamlı derecede düşük bulunmuştur $(p<0,001)$.

Sonuçlar: Işık cihazları içerisinde en yüksek sertlik değerini Valo Cordless (Ultradent - ABD) cihazı gösterirken, mavi renk kompomer en düşük sertlik değerine sahiptir.

Anahtar kelimeler: Twinky star, glasiosite, mikrosertlik, ışık cihazı

\section{ABSTRACT}

Aim: The aim of this study was to compare the microhardness value of colored compomers polymerized by three light curing units.

Material and Methods: A2 glasiosite (Voco Germany), pink Twinky Star (Voco Germany), blue Twinky star (Voco Germany) branded compomers with a thickness of $5 \mathrm{~mm}-2 \mathrm{~mm} 72$ samples were prepared. Samples have been polymerized by light curing units by Valo Cordless (Ultradent - USA), D-Light Pro (GC - Germany) and Woodpecker (China). The hardness values of the samples have been measured by the Vickers microhardness device.

Results: When assessing microhardness, there is no interaction between the colored compomer and light curing unit $(p=0,104)$ (Univariate analysis, Two way ANOVA). Comparing the microhardness values of the compomers, the GC light curing unit was found to be statistically significantly lower than Valo unit $(p<0.001)$.

Conclusions: While Valo Cordless (Ultradent-USA) shows the highest microhardness value among light-curing units, the blue compomer has the lowest microhardness value.

Keywords: Twinky Star, Glasiosite, Microhardness, Light curing unit

\section{* Atatürk Üniversitesi Diş Hekimliği Fakültesi Pedodonti Anabilim Dall, Erzurum.}

Kaynakça Bilgisi: Klıç M, Yeter G. Farklı Işık Kaynaklarının Renkli Kompomerlerin Mikrosertliği Üzerine Etkisi. Atatürk Üniv Diş Hek Fak Derg 2021; 31: 22-6.

Citation Information: Kilic M, Yeter G. The effect of different light-Curing units on the microhardness of colored compomers. J Dent Fac Atatürk Uni 2021; 31: 22-6.

\section{GİRIŞ}

Çocuklarda kabul edilebilir bir tedavi sağlanmasında, süt dişleri için kompomer olarak adlandırılan farklı renklerdeki restoratif materyaller yaygın olarak kullanılmaktadır. ${ }^{1}$ Pembe, yeşil, mavi, gümüş, limon ve altın tonları gibi renk seçenekleri üretmek için konvansiyonel komponentlere parıltılı parçacıklar eklenmiştir.
Bu uygulama ile kompomerlerin renk ve cazibesi artırımış, çocukların tedavi sırasında farklı renkleri seçerek daha fazla iş birliği yapmasına ve daha az stres yaşamasına yardımcı olunmuştur. ${ }^{2-4}$ Kompomer olarak bilinen poliasit modifiye kompozit rezinler, 1990'ların başında kullanılmaya başlanmıştır ve geleneksel kompozit rezinlerin estetiğini, cam-iyonomer simanların tutuculuğunu ve flor salınım özelliklerini birleştiren bir dental materyal olarak sunulmuşlardır. ${ }^{5}$ 
Rezin modifiye dental materyallerin polimerizasyonu için kullanılan en yaygın kürleme üniteleri ışık yayan diyot (LED) cihazlarıdır.6, 7 LED'lerin tercih edilmesinde daha düşük enerji tüketmeleri, düşük ısıya sahip olmaları ve bir fana intiyaç duymamaları gibi avantajlar rol oynamaktadır. ${ }^{8}$ LED ışık cihazları, kamphorkinon foto-başlatıcının aktivasyonu için optimum emilim dalga boyuna uyan $470 \mathrm{~nm}$ (450-490) maksimum radyan noktası ile mavi bir ışık üreten yarı iletken, indiyum galyum nitrür kullanır. ${ }^{9}$ Günümüzde çeşitli LED kürleme üniteleri kullanılmaktadır ve bu ünitelere teknolojiyle birlikte birtakım değişiklikler yapılmıştır. ${ }^{10}$ Rezin esaslı dental materyallerin polimerizasyon süreci, fiziksel özellikleri iyileştirmek ve daha iyi bir klinik performans elde etmek için önemlidir. ${ }^{11}$ Polimerizasyon derecesi birçok faktöre (ışık kılavuzu, ampulün durumu, pil ömrü) bağıdır ve rezin esaslı materyallerin mekanik özellikleri bundan etkilenmektedir. ${ }^{12}$ Önemli mekanik özelliklerden biri, dental restorasyonların yüzey sertliğidir. Yüzey sertliği, yüzey girintisine direnç anlamına gelir ve klinik performans sertlikten etkilenir. Çünkü bu, malzemenin çiğneme kuvvetlerine, aşınmaya ve ortodontik kuvvetlere direnecek kadar güçlü olup olmadığını göstermektedir..$^{13}$ Polimerizasyon derecesini değerlendirmek için en çok kullanılan dolaylı yöntemler arasında sertlik deneyleri bulunmaktadır. ${ }^{14}$ Renkli kompomerler üzerinde yapılan önceki çalışmalarda, farklı renkteki kompomerler arasında sertleşme derinliğinde önemli farklılıklar görülmüştür. ${ }^{15,16}$ Yüzeysel sertliğe renk, gölge ve materyalin tipi gibi faktörler etki eder. ${ }^{6}$ Daha açık renk tonları ( $A 1$ ve $A 1 B$ ) olan kompozitlerin, daha koyu renk tonlarına ( $A 3.5$ ve $A 3.5 B$ ) göre daha yüksek Vickers mikro sertlik değerleri gösterdiğini belirten renk ve sertlik çalışmaları literatürde mevcuttur. ${ }^{17,18}$

Rezin materyallerin polimerizasyonunda çeşitli faktörlerin yanında materyalin rengi ve ışık cihazının gücü de etkin rol oynadığından, bu çalışmada Valo, GC D-Light Pro ve Woodpecker LED ışık cihazları kullanılarak polimerize edilen Glasiosite A2, Twinky Star pembe ve mavi renkteki kompomer rezinlerin yüzey sertlikleri arasında farklıık olup olmadığının tespit edilmesi amaçlanmıştır.

\section{GEREÇ VE YÖNTEM}

Bu çalışmada Glasiosite A2 (Voco - Almanya) renkli, Twinky Star pembe ve mavi renkli (VocoAlmanya) kompomerler kullanılmıştır. Kullanılan kompomerler; BIS-GMA, diüretan-dimetilakrilat, TEGDMA ve BHT (Bütil Hidroksi Toluen) içermektedir (Tablo-1). Işık cihazları olarak Valo Cordless (Ultradent - ABD), D-Light Pro (GC - Almanya) ve Woodpecker (Çin) LED ışık üniteleri değerlendirilmiştir. GC D-Light Pro LED ışık ünitesi, çift dalga boylu bir kür lambasıdır. Çift dalga boyuna sahip iki kürleme programı sunar: Tüm rutin durumlar için; Yüksek Güç $\left(1400 \mathrm{~mW} / \mathrm{cm}^{2}\right)$ ve ISI üretimini sınırlandırmak için tercih edildiğinde; Düşük Güç $\left(700 \mathrm{~mW} / \mathrm{cm}^{2}\right)$ özelliği vardır. Valo Cordless, ışıkla sertleşen tüm dental materyalleri polimerize edecek kapasitede, 395-480 nm arasında yüksek şiddetli ışık üreten özel, geniş dalga boylu ışık yayan bir diyot (LED) kullanır. 3 farklı güç modunda çalışabilir. Bunlar; Standart Güç $\left(1000 \mathrm{~mW} / \mathrm{cm}^{2}\right)$, Yüksek Güç $(1400 \mathrm{~mW} /$ $\left.\mathrm{cm}^{2}\right)$ ve Ekstra Güç $\left(3200 \mathrm{~mW} / \mathrm{cm}^{2}\right)$ olarak sınıflandırılmaktadır. Woodpecker ise $850 \mathrm{~mW} / \mathrm{cm}^{2}-1000 \mathrm{~mW} / \mathrm{cm}^{2}$ güce sahip ve 3 ayrı mod kullanarak çalışabilen (sabit, artan, aralıklı) LED ışık ünitesidir. Çalışmamızda DLight Pro cihazının düşük gücü, Valo cihazının standart gücü ile Woodpecker cihazının sabit gücü kullanılmıştır (Tablo-2). Yapılan power analizine göre $a=0,05,1-\beta$ (güç) $=0,80$ alındığında her bir grupta en az 6 'şar örnek alınması gerektiği belirlenmiştir. Bu çalışmada 3 farklı kompomer rengi seçilmiştir. Her grupta 8 örnek olacak şekilde toplamda 72 örnek hazırlanmıştır $(n=8)$. Çalışmada kullanılacak örnekler için Vickers sertlik cihazına uyacak şekilde $5 \mathrm{~mm}$ çapında ve $2 \mathrm{~mm}$ kalınlığında teflon kalıplar kullanılmıştır. Kompomerlerin üç renginden hazırlanan 72 örnek Valo, GC ve Woodpecker ışık cihazıyla polimerize edilmek üzere 3 eşit gruba ayrılmıştır $(n=24)$. Materyalin teflon kalıba yerleştirilmesinden sonra, teflon kalıp alt ve üst yüzeyinden bir şeffaf bantla kaplanmış, hava kabarcığı oluşmaması ve fazla kompomer rezinin çıkarılması için iki cam plaka arasında sıkıştırılmıştır. Böylelikle oksijen inhibasyon tabakasının oluşumunun engellenmesi hedeflenmiştir. Işık cihazının ucu polimerizasyon sırasında cam plakayla sıkı temas halinde tutulmuştur. Her üç ışık cihazı için 20 sn süreyle polimerizasyon gerçekleştirilmiştir. Polimerize edilen örnekler, deforme olmayacak şekilde teflon kalıplardan ayrılmış, üst yüzeylerinin anlaşılabilmesi için kurşun kalem ile işaretleme yapılmıştır. Farklı bölmelere sahip kutularda, ışık geçirmeyecek şekilde distile su içerisinde 24 saat bekletilmiştir. Yüzey sertliği, her bir numunenin üst yüzeyi için Vickers sertlik cihazı ile 10 saniyede 100 gr'lık bir kuvvetle 100 mikrometre aralıklarla altışar ölçümle kaydedilmiştir. Her numunenin ortalama Vickers sertlik değeri hesaplanmıştır. Mikro sertlik verilerinin istatistik analizlerinde SPSS versiyon 21 kullanılmıştır. Kompo- 
mer ve ışık cihazı grupları arasındaki interaksiyon için çift yönlü ANOVA, kompomer ve ışık cihazları arasındaki farklıık için Kruskal Wallis testi, grup içi farklılıkların belirlenmesi için de Mann Whitney $U$ analizi kullanılmıştır.

Tablo 1. Üretici firmadan alınan materyal içeriği

\begin{tabular}{|l|c|c|c|c|}
\hline Materyal & Kategori & İçerik & $\begin{array}{c}\text { Üretici } \\
\text { Firma }\end{array}$ & $\begin{array}{c}\text { Renk } \\
\text { Tonu }\end{array}$ \\
\hline Twinky Star & $\begin{array}{l}\text { Poliasit Modifiye } \\
\text { Kompozit Rezin }\end{array}$ & $\begin{array}{c}\text { BIS-GMA, } \\
\text { diüretandimetilakrilat, } \\
\text { TEGDMA, BHT }\end{array}$ & $\begin{array}{c}\text { Voco- } \\
\text { Almanya }\end{array}$ & Mavi* \\
\hline Twinky Star & $\begin{array}{l}\text { Poliasit Modifiye } \\
\text { Kompozit Rezin }\end{array}$ & $\begin{array}{c}\text { BIS-GMA, } \\
\text { diüretandimetilakrilat, } \\
\text { TEGDMA, BHT }\end{array}$ & $\begin{array}{c}\text { Voco- } \\
\text { Almanya }\end{array}$ & Pembe* \\
\hline Glasiosite & $\begin{array}{l}\text { Poliasit Modifiye } \\
\text { Kompozit Rezin }\end{array}$ & $\begin{array}{c}\text { BIS-GMA, } \\
\text { diüretandimetilakrilat, } \\
\text { TEGDMA, BHT }\end{array}$ & $\begin{array}{c}\text { Voco- } \\
\text { Almanya }\end{array}$ & $\mathrm{A} 2$ \\
\hline
\end{tabular}

* Özel renk efektleri ve simli etki herhangi bir metal madde kullanılmadan Glimmer (çözülmez bir mineral) sayesinde elde edilmektedir.

Tablo 2. Kompomerlerin polimerizasyonunda kullanılan ışık üniteleri

\begin{tabular}{|c|c|c|c|c|}
\hline $\begin{array}{c}\text { Işıkla } \\
\text { Polimerizasyon } \\
\text { Ünitesi }\end{array}$ & Üretici Firma & Lamba & $\begin{array}{c}\text { Kullanılan } \\
\text { Işık } \\
\text { Şiddeti } \\
\left(\mathbf{m W} / \mathbf{c m}^{2}\right)\end{array}$ & $\begin{array}{c}\text { Kullanılan } \\
\text { Işınlama } \\
\text { Süresi } \\
\text { (sn) }\end{array}$ \\
\hline Valo Cordless & $\begin{array}{l}\text { Ultradent- } \\
\text { ABD }\end{array}$ & $\begin{array}{l}\text { Işık } \\
\text { Yayan } \\
\text { Diyot }\end{array}$ & 1000 & 20 \\
\hline D-Light Pro & GC-Almanya & $\begin{array}{c}\text { Işıı } \\
\text { Yayan } \\
\text { Diyot }\end{array}$ & 700 & 20 \\
\hline LED-D & $\begin{array}{l}\text { Woodpecker- } \\
\text { Çin }\end{array}$ & $\begin{array}{l}\text { Işık } \\
\text { Yayan } \\
\text { Diyot }\end{array}$ & 850 & 20 \\
\hline
\end{tabular}

\section{BULGULAR}

Yüzey sertliği değerlendirildiğinde kompomer rengi ve ışık cihazı arasında etkileşim bulunmamaktadır $(p=0,104)$ (Univariate analysis, Two way anova). Kompomerlerin yüzey sertlik değerleri karşılaştırıldığında GC ışık cihazı Valo'dan istatistiksel olarak anlamlı derecede düşük bulunmuştur $(p<0,001)$. Sadece, Valo ışık cihazı kullanıldığında farklı kompomer renkleri için benzer yüzey sertlik değerleri elde edilmiştir ( $p=$ $0,178)$. Valo ışık cihazının yüzey sertlik değerleri dışında diğer iki ışık cihazının farklı kompomer renklerinden elde edilen yüzey sertlik değerleri arasındaki farklılık, istatistiksel olarak anlamlı bulunmuştur $(p<0.05)$. Bütün ışık cihazları değerlendirildiğinde mavi renkli kompomerin en düşük yüzey sertlik değeri gösterdiği ista- tistiksel olarak anlamlı bulunmuştur $(p<0,001)$. Mavi ve beyaz örneklerde yüzey sertlik değeri en yüksek Valo ışık cihazında elde edilmiş ancak ışı cihazları arasındaki fark istatistiksel olarak anlamlı bulunmamıştır ( $p=0.069,0.608)$. Pembe örneklerde ise yüzey sertlik değeri yine en yüksek Valo ışık cihazında elde edilmiş ve aralarındaki fark istatistiksel olarak anlamlı bulunmuştur $(p=0,012)$ (Tablo-3).

Tablo 3. Farklı ışık cihazları kullanılarak polimerize edilen kompomerlerin sertlik değerleri (Ortalama \pm standart sapma)

\begin{tabular}{|c|c|c|c|c|c|}
\hline & GC & Woodpecker & Valo & Genel & p \\
\hline Mavi & $30,45 \pm 2,43^{\mathrm{m}}$ & $31,82 \pm 4,01^{\mathrm{m}}$ & $35,15 \pm 5,04$ & $32,47 \pm 4,3^{\mathrm{m}}$ & 0,069 \\
\hline Pembe & $31,46 \pm 4,73^{\mathrm{a}, \mathrm{m}}$ & $36,8 \pm 2,84^{\mathrm{b}}, \mathrm{n}$ & $39,49 \pm 5,2^{\mathrm{b}}$ & $35,92 \pm 5,39^{\mathrm{n}}$ & 0,012 \\
\hline Beyaz & $38,15 \pm 2,24^{\mathrm{n}}$ & $38,02 \pm 3,03^{\mathrm{n}}$ & $39,18 \pm 2,98$ & $38,45 \pm 2,7^{\mathrm{n}}$ & 0,608 \\
\hline Genel & $33,35 \pm 4,72^{\mathrm{a}}$ & $35,55 \pm 4,2^{\mathrm{ab}}$ & $37,94 \pm 4,77^{\mathrm{b}}$ & $35,61 \pm 4,89$ & $<0,001$ \\
\hline P & 0,003 & 0,007 & 0,178 & $<0,001$ & 0,104 \\
\hline
\end{tabular}

\section{TARTIŞMA}

Bu çalışma hem ışık cihazları arasında hem de kompomer renkleri arasında yüzey sertliği bakımından önemli bir fark olabileceğini düşündürebilir. Çalışmamızda kullanılan farklı renklerdeki kompomerlerin formülasyonları aynı olduğu için polimerizasyon farklııkları, farklı renkler için ihtiva ettikleri pigmentlerin türü ve miktarından kaynaklanıyor olabilir. ${ }^{19}$ Üretici, twinky star ve glasiosite birleşiminin geleneksel kompomerlere benzediğini ve aralarındaki tek farkın yapıya eklenen pigmentler olduğunu belirtmiştir. Yüzey sertliğinin farklı renklerde değişmesi, pigmentlerin organik ya da inorganik olmasına ya da ışığın farklı renkler de farklı miktarda emilmesine bağlı olabilir.6, 20 Kompomerin rengi, pigmentin türünden ve içeriğinden etkilenir. ${ }^{13}$ Örneğin, $\mathrm{TiO}_{2}$ dolgu maddelerinin içine katıldığında reçinenin opaklığını artıran bir pigmenttir. ${ }^{21}$ Çocukların iş birliğini geliştirmek için kullanılan renkli kompomerlerin içindeki pırıltılı parçacıklar ve renk pigmentleri konvansiyonel renk tonlarını takip etmemektedir. ${ }^{9}$ Yapılan bir çalışmada renk pigmentlerinin ve pırıltılı parçalıkların homojen dağılım göstermediği belirtilmiştir. ${ }^{6} \mathrm{Bu}$ durum da ışık absorbsiyonunun her yerde eşit dağılmayacağına işaret edebilir. Kompozit rezinlerin ve diğer materyallerin sertliği ile ilgili yapılan çok sayıda çalışma çeşitli renk pigmentleri ve ışıltılı materyalleri içeren renkli kompomerlerin, mikrosertlik ve ışık geçirgenliği üzerindeki etkilerini aydınlatmak için yeterli olamayabilir. ${ }^{19}$ Geçirgenlik spektral dağılımı numunenin renginden etkilenir. Beyaz renkli numunelerin sertlik derecesi için yapılmış çok sayıda çalışma mevcut iken literatürde renkli kompomerlerin değerlendirilmesini sunan çalışma sayısı

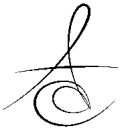


azdır. ${ }^{9,} 18$ Bir çalışma altın, portakal ve limon renkli numunelerin daha düşük geçirgenliğe, mavi ve gümüş renkli kompomer numunelerin daha yüksek geçirgenliğe sahip olduğunu bulmuştur. ${ }^{19}$ Bizim çalışmamızda ise bu çalışmanın aksine beyaz ve pembe kompomere kıyasla mavi numunelerin sertlik değeri daha düşük belirlenmiştir. Numunelerin yüksek geçirgenlik göstermesi sertlik derecesini etkiliyor olabilir. Numunelerin kalınlıkları ve kullanılan ışık cihazları da geçirgenlik spektral dağılımını etkileyebilir diye düşünmekteyiz. Aynı zamanda bu farklıığa ışıkla sertleşen birimler arasındaki değişiklikler, örneklem büyüklükleri, farklı test koşulları, vickers cihazının tipindeki farklılıklar, enerji miktarındaki farklılıklar ve numuneleri oluşturmak için kullanılan zamanın farklı olması sebep olmuş olabilir. ${ }^{18,} 22$ Jafari ve ark. ${ }^{23}$ LED üniteleri kullanarak renkli kompomerlerin farklı renklerinin yüzey sertliği üzerinde gerçekleştirdikleri çalışmada sonuçlarımızla tutarlı bir şekilde en düşük sertliğin mavi renkle ilişkili olduğunu göstermişlerdir. Bu sonuçlar, daha koyu renklerdeki pigmentlerin daha fazla ışık alabileceğini ve bu yüzden ışığın rezine nüfuz etme derinliğinin azalabileceğini düşündürebilir. ${ }^{6}$ Yine ışık cihazının yaydığı mavi ışık ile mavi kompomer numunelerinin pigmentleri aynı renkte olduğundan dolayı ışığın saçılmasına sebep olurken pembe ve beyaz pigmentlerin mavi ışıkla zıt kombinasyon oluşturduğundan daha yüksek geçirgenlik göstermesi de bu durumu açıklayabilir. ${ }^{19}$ Farklı bulunan sonuçlara, pırıltılı parçacıkların ve renk pigmentlerinin homojen dağılmaması nedeni ile ışı̆ı̆n saçılımının her numunede değişik olması sebep olabilir. ${ }^{24}$ Hwang ve ark. ${ }^{6}$ ışık iletiminin dağıtımının pırıltılı parçacıklardan etkilenebileceğini ve pırıltılı parçacıkların malzemenin sertlik değerini etkileyebilecek düzensiz şekil ve boyutlar içerdiğini SEM altında incelemişlerdir. Bu yüzden farklı renklerde farklı pırıltılı parçacık ve renk pigmentine sahip kompomerlerin farklı sertlik değeri sergileyebileceğini söylemişlerdir.

Bu çalışmada LED'ler içinde en yüksek sertlik değerinin Valo ışık cihazı kullanıldığında elde edildiği görülmüştür. LED ile kompozit rezinler üzerinde yapılan bir çalışma Valo ışık cihazının mikro sertlik değerini diğer cihazlara göre daha yüksek bulmuştur. ${ }^{25}$ Gönülol ve ark. ${ }^{20}$ yaptıkları çalışmada kullanılan farklı ışık cihazları içerisinde Valo ışık cihazının bizim çalışmamızda kullanılan modunun sertlik değerini diğer ışık cihazlarına kıyasla yüksek bulmuşlardır. Işık cihazları ve rezin içerikli materyaller ile yapılan çalışmalar bazen cihazların tipine bazen de polimerizasyon sürelerine göre sertlik değeri bakmış ve farklı sonuçlar bulmuşlardır. ${ }^{17,20,26}$ Işık cihazları arasındaki farklılıklara, ışık cihazların güç ve voltajlarının eşitlendiği modlarının olmaması, numunelerin standart bir kriter altında hazırlanmamış olması sebep olmuş olabilir.

Çalışmamızın çeşitli sınırlııkları vardır, bunların arasında tüm kompomer renklerinin çalışmaya dahil edilmemesi, kompomer içeriğinin ve pigmentlerin SEM görüntülerinin alınmaması ya da homojen dağılıp dağılmadığına bakılmaması, kompomer içeriklerinin aynı olduğu konusunda üretici firmanın doğruluğunun teyit edilmemesi ve kliniğimizde kullanılan ışık cihazları ile beraber indirekt polimerizasyon yöntemlerinin değerlendirilmemesi sayılabilir.

\section{SONUÇLAR}

$\mathrm{Bu}$ çalışmanın sınırları içerisinde mavi renk kompomerlerin, pembe ve beyaz renge göre daha düşük sertlik değerine sahip olduğu görülmüştür. Işık cihazları içerisinde Valo'nun standart gücü kompomerler üzerinde en yüksek sertlik değeri göstermiştir. Çocuk diş hekimliğinde çocukların motivasyonunda sık tercih edilen renkli kompomerlerin yeterli polimerizasyon derinliğine ulaşması için geliştirilmesine ihtiyaç duyulmaktadır.

\section{NOT:}

$\mathrm{Bu}$ çalışma, çalışmayı yürüten tüm yazarlar tarafından okunmuş ve onaylanmış orijinal bir çalışmadır. Herhangi bir yazar, kurum ya da kuruluş ile çıkar çatışması olmadığını belirtmek isteriz.

Yazarlar, çalışmanın verilerinin istatistiksel değerlendirmesinde emeği geçen Dr. Öğr. Üyesi Fatih ŞENGÜL'e teşekkür eder.

\section{KAYNAKLAR}

1. Ehlers V, Gran K, Callaway A, Azrak B, Ernst C-P. One-year clinical performance of flowable bulk-fill composite vs. Conventional compomer restorations in primary molars. J Adhes Dent 2019; 21: 247-54.

2. Olegário IC, Hesse D, Mendes FM, Bonifácio CC, Raggio DP. Glass carbomer and compomer for art restorations: 3-year results of a randomized clinical trial. Clin Oral Invest 2019; 23: 1761-70.

3. Hugar SM, Kohli D, Badakar CM, Gokhale NS, Thakkar PJ, Mundada MV. An in vivo comparative evaluation of dental anxiety level and clinical success rate of composite and multicolored compomers in 6 to 12 years of children. International J Clin Pediatr Dent 2018, 11: 483.

4. Guler C, Keles A, Guler MS, Karagoz S, Cora ÖN, Keskin GJJOaB, Materials F. Thermal conductivity of different colored compomers. J Appl Biomater \& Funct Mater 2017;15: e362-8. 
5. Ruse ND. What is a" compomer"? J Canadian Dent Assoc 1999; 65: 500-4.

6. Hwang S-W, Kwon T-Y, Kim K-H, Kwon Y-H, Kim $\mathrm{H}$, Lee J-B. Optical, mechanical and chemical properties of colored compomer. Biomed Res 2007, 11: 36-42.

7. Croll TP, Helpin ML, Donly KJ. Multi-colored dualcured compomer. Pediatr Dent 2004, 26: 273-6.

8. Behnaz $E$, Hengameh $S$, Assila V. Hardness evaluation of composite resins cured with qth and led. J Dent Rese Dent Clin Dent Prosp 2014; 4; 8: 40-4

9. Atabek D, Bodur H, Kalayci Ş, Tirali E. Conversion degrees of a colored compomer in different colors utilized by various curing times. J Dent Child 2011; 78: 83-7.

10. Salgado VE, Borba MM, Cavalcante LM, De Moraes RR, Schneider LF. Effect of photoinitiator combinations on hardness, depth of cure, and color of model resin composites. J Esthetic Res Dent 2015; 27: S41-8.

11. Lima RBW, Troconis CCM, Moreno MBP, Murillo-Gómez F, De Goes MF. Depth of cure of bulk fill resin composites: A systematic review. J Esthetic Res Dent 2018; 30: 492-501.

12. Gan J, Yap A, Cheong J, Arista N, Tan C. Bulk-fill composites: Effectiveness of cure with poly-and monowave curing lights and modes. Oper Dent 2018; 43: 136-43.

13. Bakkal M, Yılmaz B, Durmus A, Durmus Z, Ozalp S. Polymerization characteristics of colored compomers cured with different led units. J Appl Biomater Func Mater 2019; 17: 2280800019827805.

14. Gorken FN, Kuru S, Batu S, Guven Y, Sepet E. Compomers reinforced with bioactive glass and hydroxyapatite particles. Oral Health \& Prev Dent 2018; 16: 431-8

15. Park S-H, Kim S-S, Cho Y-S, Lee S-Y, Noh B-D. Comparison of linear polymerization shrinkage and microhardness between qth-cured \& led-cured composites. Operativ Dent 2005; 30: 461-7.

16. Okte Z, Villalta P, Garcia-Godoy F, Garcia-Godoy F, Murray P. Effect of curing time and light curing systems on the surface hardness of compomers. Oper Dent Univ Washington 2005; 30: 540.

17. Yapar Mİ, Çelik N, Sağsöz Ö, Karalar B, Seven N, Bayındır YZ. Farklı polimerizasyon tekniklerinin kompozit rezinlerin mekani ve fiziksel özelliklerine etkisi. Atatürk Üniv Diş Hek Fakültesi Derg 2020; 30: 26-32.

18. Briso A, Dos PS, Fagundes T. Influence of lightcuring units on surface microhardness and color change of composite resins after challenge. J Contemp Dent Practic 2019; 20: 204-10.

19. Khodadadi E, Khafri S, Aziznezhad M. Comparison of surface hardness of various shades of twinky star colored compomer light-cured with qth and led units. Electronic physician, 2016, 8: 2355.

20. Gonulol N, Ozer S, Tunc ES. Effect of a thirdgeneration led lcu on microhardness of tooth-c olored restorative materials. Int J Pediatr Dent 2016; 26: 376-82.

21. Yoshida K, Taira Y, Atsuta M. Properties of opaque resin composite containing coated and silanized titanium dioxide. J Dent Res 2001; 80: 864-8.

22. Marigo L, Nocca G, Fiorenzano G, Callà C, Castagnola R, Cordaro M, Paolone G, Sauro S. Influences of different air-inhibition coatings on monomer release, microhardness, and color stability of two composite materials. BioMed Res Int 2019.

23. Jafari Z, Javadinejad S, Mirzakochaki P. Evaluation of colored compomer micro-hardness with different colors in various time curing. Daneshvar Med 2015; 22: 17-24.

24. Nicholson JW. Polyacid-modified composite resins ("compomers") and their use in clinical dentistry. Dental materials, 2007, 23: 615-622.

25. Deniz Arısu $H$, Eligüzeloglu Dalkilic $E$, Alkan $F$, Erol $S$, Uctasli MB, Cebi A. Use of artificial neural network in determination of shade, light curing unit, and composite parameters' effect on bottom/top vickers hardness ratio of composites. BioMed Res Int 2018.

26. Duruk G, Kizilci E, Kiliç MÇ. Rezin kompozitlerin mikrosertliğine kompozit kalınlıkları ve ışınlama sürelerinin etkisi. Türkiye Klinikleri Çocuk Diş Hekimliği-Özel Konular 2015; 1: 37-41.

\section{Sorumlu Yazarın Yazışma Adresi Dr. Öğr. Üyesi Münevver KILIÇ}

Atatürk Üniversitesi Diş Hekimliği Fakültesi Pedodonti Anabilim Dall, Erzurum. E-mail: mnvvr_25@hotmail.co 